\title{
Siderophores of fungi from Lipa clay loam soil, Philippines
}

\author{
Jonathan Jaime G. Guerrero ${ }^{1, *}$, Teresita U. Dalisay ${ }^{2}$, Ireneo B. Pangga ${ }^{2}$, Nolissa D. Organo ${ }^{3}$
}

\begin{abstract}
This research was conducted to isolate culturable soil-borne fungi from Lipa clay loam soil and identify the types of siderophores they produce. The frequency of fungal isolates was likewise compared across the soil strata. Soil samples were plated on Rose Bengal Agar (RBA) and incubated for five days. Morpho-culturally unique isolates were transferred in Potato Dextrose Agar (PDA) slants and identified using taxonomic keys and by ITS sequencing. Siderophores of each species were then characterized through colorimetric methods. Twenty-nine species of fungi were identified. Six isolates were Basidiomycetes, 1 Zygomycetes and 22 Ascomycetes. Among ascomycetes, two were teleomorphs: Chaetomium globosum Kunze and Emericella nidulans (Eidam) Vuillemin. Isolates were then characterized in terms of their ability to produce siderophores. Majority produced hydroxamate type of siderophores while only Aspergillus tamarii Kita produced all three types of siderophores. Six other species failed to produce any of the three types. Isolates may further be studied for their metal remediating capacity and other biological activities.
\end{abstract}

Keywords: Chaetomium globosum, Emericella nidulans, Lipa clay loam soil, siderophores, soil-borne fungi

\section{Introduction}

Many fungi inhabit the soil and perform multiple functions. Beneficial fungi include decomposers, mutualists and antagonists of pathogenic species. Pathogenic ones are either soil-borne or overwinter in the soil during their saprogenic stages. It is estimated that majority of the fungi named are residents of the soil (Bridge and Spooner, 2001). Because of the differential characteristics of soils, fungal composition greatly varies among soil ecosystems. Unique soil-borne fungi can be identified, and their potential applications may be harnessed. One soil type needing fungal characterization is the Lipa clay loam soil.

The Lipa soil series are characteristically undulating to rolling and provides moderately well drainage capabilities. Soils in this series are classified as fine, clayey, mixed, shallow,

\footnotetext{
${ }^{1}$ Department of Biology, College of Science, Bicol University, Legazpi City, Philippines

${ }^{2}$ Institute of Weed Science, Entomology and Plant Pathology, College of Agriculture and Food Sciences, University of the Philippines - Los Baños, College, Laguna, Philippines

${ }^{3}$ Division of Soil Science, College of Agriculture and Food Sciences, University of the Philippines, College, Laguna, Philippines

*Corresponding email: jonathanjaime.g.guerrero@gmail.com

Date Submitted: 03 May 2019

Date Accepted: 13 March 2020
}

isohyperthermic Typic Eutrudepts and are residual soils of volcanic tuff. The surface soil, $25-30 \mathrm{~cm}$ in depth is dark brown, brown to light brown in color, loose, fine loam. The texture ranges from loam to clayey loam or silty clay loam. In older landscapes, the subsurface horizon is mainly clayey and has medium, angular blocky structure, and sticky and plastic consistency (Carating et al., 2014).

One characteristic of fungal isolates this research wanted to elucidate is their ability to produce chelating substances collectively known as siderophores. Traditionally, siderophores are known only by being iron chelators. Ferric hydroxide has extreme insolubility which limits free iron in aerobic environment. This biological need to access iron is important for microorganisms in the soil to proceed with metabolic processes such as reduction of oxygen for ATP synthesis, reduction of ribotide precursors of DNA, for formation of heme, among many other functions. Similarly, excessive iron can also be toxic because of its catalytic role in the formation of oxidizing radicals from superoxide and peroxide (Loper and Buyer, 1991). As a response, fungi can either release high-affinity ferric iron reductase or synthesize siderophores. Microorganisms have evolved siderophores as a biochemical means to tap on the rich iron deposit of the soil, regulating the amount they incorporate and transporting them into the cell.

Siderophore identification is an important step towards identification of fungi capable of metal remediation. Thus, this research aimed to isolate culturable fungi from Lipa clay loam soil and characterize each isolate in terms of their morpho- 
cultural characteristics and the corresponding siderophores they produced.

\section{Materials and Methods}

\section{Sampling of Lipa Clay Loam Soil}

Soil used in this research was collected from the University of the Philippines at Los Baños (UPLB) grounds in

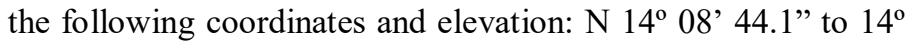
$08^{\prime} 45.1^{\prime \prime}$ and $\mathrm{E} 121^{\circ} 15^{\prime} 42.4^{\prime \prime}$ to E $121^{\circ} 15^{\prime} 43.5^{\prime \prime}, 29.8$ to 33.6 masl. The soil in UPLB belongs to the Lipa soil series and shows characteristics of clay loam soil. Specifically, the sampling site was at the lower campus near the Institute of Plant Breeding, characterized by patches of grass vegetation and few ornamental plants. A soil auger was used to take a soil core. Each soil core was carefully separated based on the following depths: $0-5 \mathrm{~cm}, \quad 6-10 \mathrm{~cm}, 11-20 \mathrm{~cm}$, and 21-30 cm. Approximately $25 \mathrm{~kg}$ of soil from each soil depth was taken. All samples from the same soil depth were combined to form one composite sample for use in the isolation of fungi. A subsample of the soil was subjected to soil analysis for determination of the following edaphic characteristics: $\mathrm{pH}$, soil moisture, clay, silt and sand composition, and available nitrogen $(\mathrm{N})$, phosphorus $(\mathrm{P})$ and potassium $(\mathrm{K})$.

\section{Isolation and Identification of Soil Mycoflora}

Four replicates of soil with $25 \mathrm{~g}$ each were processed for isolation of soil mycoflora from each of the collection sites. Twenty-five (25) grams of soil was diluted in $100 \mathrm{~mL}$ of sterile distilled water to form the stock solution. Aliquot $(1.0 \mathrm{~mL})$ of the stock solution was transferred to $9.0 \mathrm{~mL}$ of sterile distilled water to form a 10 -fold dilution $\left(10^{-1}\right)$. A serial transfer was done up to a 100,000 -fold dilution $\left(10^{-5}\right)$. One milliliter each of dilution was plated on freshly prepared Rose Bengal Agar (RBA), amended with streptomycin, using spread plate technique. First to the fifth dilutions were plated in triplicate and incubated for $5 \mathrm{~d}$ at room temperature. Colonies showing various characteristics based on morphological and visual cultural assessment were transferred into fresh potato dextrose agar (PDA) slants and assigned a morphospecies code.

Isolates were morphologically and culturally characterized to aid in identification through light microscopy and scanning electron microscopy. Agar block technique was utilized to grow fungi and document the formation of fruiting structures. Identification of isolates was aided by morphological keys, primarily that of Watanabe (2010) on soil and seed fungi, and Samuels and Hebbar (2015) on Trichoderma species. All isolates were deposited at the UPLB Museum of Natural History Microbial Culture Collection and were assigned unique deposit codes (Table 1).

Likewise, fungal DNAs were extracted from the cultures using the Zymo Quick-DNA ${ }^{\mathrm{TM}}$ fungal Miniprep Kit (Catalog No. D6005) following manufacturer's instructions. Extracted DNAs were amplified using the primers ITS $15^{\prime}$ (TCC GTA GGT GAA CCT GCG G) 3' and ITS 4 5' (TCC TCC GCT TAT TGA TAT GC) 3' and sent to Macrogen Korea for ITS sequencing. The resulting nucleotide sequences were cleared of noises and aligned using ChromasPro and Mega7 softwares. Identities of the isolates were determined by homology search from the National Center for Biotechnology Information (NCBI) database using Basic Local Alignment Search Tool (BLAST). Those with $97 \%$ or higher homology percentage were accepted. Fungal diversity was determined using the software Biodiversity Pro (McAleece et al., 1997).

\section{Chemical Assays for Detection of Specific Types of Siderophores}

Detection of specific types of siderophores followed the methods described by Payne (1994), Dave and Dube (2000) and Shenker et al. (1992). Cultures were grown in 10-mL Potato Dextrose Broth (PDB) (Kumari and Kaviyarasan, 2014; VanderMolen et al., 2012) for $21 \mathrm{~d}$ at $25-30^{\circ} \mathrm{C}$ (room temperature) and centrifuged at 10,000 rpm for 15-20 min. Cellfree supernatants were used for the chemical tests.

\section{Detection of Hydroxamate Siderophores (Tetrazolium Test)}

One to two drops of $2 \mathrm{~N} \mathrm{NaOH}$ and $0.1 \mathrm{~mL}$ of test sample were added to a pinch of tetrazolium salt. Formation of a deep red color indicated the presence of hydroxamate siderophore.

\section{Detection of Catecholate Siderophores}

Freshly prepared $2 \%$ aqueous ferric chloride $\left(\mathrm{FeCl}_{3}\right)(1.0$ $5.0 \mathrm{~mL}$ ) was added to $1.0 \mathrm{~mL}$ of the test sample. Formation of red wine color and maximum absorbance at $495 \mathrm{~nm}$ indicated presence of catecholate siderophores.

\section{Detection of Carboxylate Siderophores (Vogel Test)}

Three drops of $2 \mathrm{~N}$ sodium hydroxide $(\mathrm{NaOH})$ were mixed with 1 drop of phenolpthalein. Water was added until light pink color developed. Disappearance of the color upon addition of 1 $\mathrm{mL}$ sample indicated the presence of carboxylate siderophores.

\section{Results and Discussion}

\section{Characterization of Lipa Clay Loam Soil Samples}

Analysis of Lipa clay loam soil showed the following composition: $39.62 \%$ silt, $33.16 \%$ clay, and $27.23 \%$ sand. Organic matter content was at $3.6 \%$ with a $\mathrm{pH}$ of 5.4 . Available 
Table 1. Deposit and accession numbers of fungal isolates at the Microbial Culture Collection, Museum of Natural History, University of the Philippines Los Baños, Philippines and the National Center for Biotechnology Information Genbank.

\begin{tabular}{|c|c|c|c|}
\hline Isolation code $^{1}$ & Identity & Deposit Code ${ }^{2}$ & Accession Number ${ }^{3}$ \\
\hline JJGG-71 & Aspergillus brasiliensis & MCC-MNH 2514 & MK644021 \\
\hline JJGG-73 & Aspergillus versicolor & MCC-MNH 2515 & MK644120 \\
\hline JJGG-54 & Aspergillus terreus & $M C C-M N H 2516$ & MK644096 \\
\hline JJGG-66 & Aspergillus aculeatus & MCC-MNH 2517 & - \\
\hline JJGG-37 & Acrophialaphora levis & MCC-MNH 2518 & MK646060 \\
\hline JJGG-40 & Aspergillus flaviceps & MCC-MNH 2519 & MK645221 \\
\hline JJGG-26 & Aspergillus flavus & MCC-MNH 2520 & MK645222 \\
\hline JJGG-63 & Aspergillus fumigatus & MCC-MNH 2521 & MK644062 \\
\hline JJGG-64 & Aspergillus tamarii & MCC-MNH 2522 & - \\
\hline JJGG-65 & Aspergillus tubingensis & MCC-MNH 2523 & MK644176 \\
\hline JJGG-38 & Penicillium pinophilum & $M C C-M N H 2524$ & MK646032 \\
\hline JJGG-30 & Penicillium polonicum & MCC-MNH 2525 & MK64603 \\
\hline JJGG-55 & Penicillium solitum & MCC-MNH 2526 & MK567887 \\
\hline JJGG-51 & Penicillium citrinum & MCC-MNH 2527 & - \\
\hline JJGG-36 & Talaromyces radicus & $M C C-M N H 2528$ & MK646059 \\
\hline JJGG-67 & Talaromyces pinophilus & MCC-MNH 2529 & MK646041 \\
\hline JJGG-41 & Rigidoporus vinctus & $M C C-M N H 2530$ & MK646062 \\
\hline JJGG-50 & Schizophyllum commune & MCC-MNH 2531 & MK680083 \\
\hline JJGG-74 & Emericella nidulans & MCC-MNH 2532 & MK646070 \\
\hline JJGG-52 & Trichoderma erinaceum & $M C C-M N H 2533$ & - \\
\hline JJGG-45 & Trichoderma harzianum & MCC-MNH 2534 & MK646064 \\
\hline JJGG-53 & Fusarium sublunatum & MCC-MNH 2535 & - \\
\hline JJGG-33 & Chaetomium globosum & MCC-MNH 2510 & - \\
\hline JJGG-46 & Mortierella sp. & MCC-MNH 2536 & - \\
\hline JJGG-44 & Trametes maxima & MCC-MNH 2537 & MK646061 \\
\hline JJGG-49 & Fomitopsis meliae & MCC-MNH 2538 & MK646068 \\
\hline JJGG-32 & Emmia lacerata & MCC-MNH 2539 & - \\
\hline JJGG-42 & Talaroymces verruculosus & $M C C-M N H 2540$ & - \\
\hline JJGG-43 & Lentinus sp. & $M C C-M N H 2541$ & MK646067 \\
\hline
\end{tabular}

${ }^{1}$ unique strain identifier

${ }^{2}$ deposit number at the UPLB-Museum of Natural History

${ }^{3}$ accession number at the National Center for Biotechnology Information

$\mathrm{P}$ was $11 \mathrm{ppm}, \mathrm{K}$ at $2.05 \mathrm{me} / 100 \mathrm{~g}$ of soil, while total $\mathrm{N}$ was $0.19 \%$. Soil CEC was $40.06 \mathrm{me} / 100 \mathrm{~g}$ of soil. Zinc and $\mathrm{Cu}$ were also analyzed to provide baseline for initial concentration in the soil. $\mathrm{Zn}$ was found to be at $2 \mathrm{ppm}$ while $\mathrm{Cu}$ was at $9 \mathrm{ppm}$.

\section{Identification andCharacterization of Fungal Isolates}

A total of 29 species were identified by morphological and molecular techniques (Table 1). Amplification of all fungi using ITS1 and ITS4 primers yielded fragment length of 580-750 bp, all falling within the expected range for the primers used. Basidiomycetes accounted for $20.67 \%$ (6 out of 29 species) of isolates. Among Ascomycetes, only 2 were teleomorphic. These were Chaetomium globosum Kunze and Emericella nidulans (Eidam) Vuillemin that form perithecium and cleistothecium, respectively. These coelomycetes were photomicrographed under the scanning electron microscope to observe their ascoma and spores. Of the remaining ascomycetes, 9 were Aspergillus, 4 were Penicillium, 3 Talaromyces, and 2 Trichoderma species. Representatives of each group are presented for reference in the accompanying figures (1-8). The rest of the isolates belonged to individual genera. One species, Morteriella sp., belonged to Zygomycota. The hyphomycetes were members of only three families: Trichocomaceae, Nectriaceae, and Hypocreaceae. They are common soil inhabitants, mostly with a saprophytic 


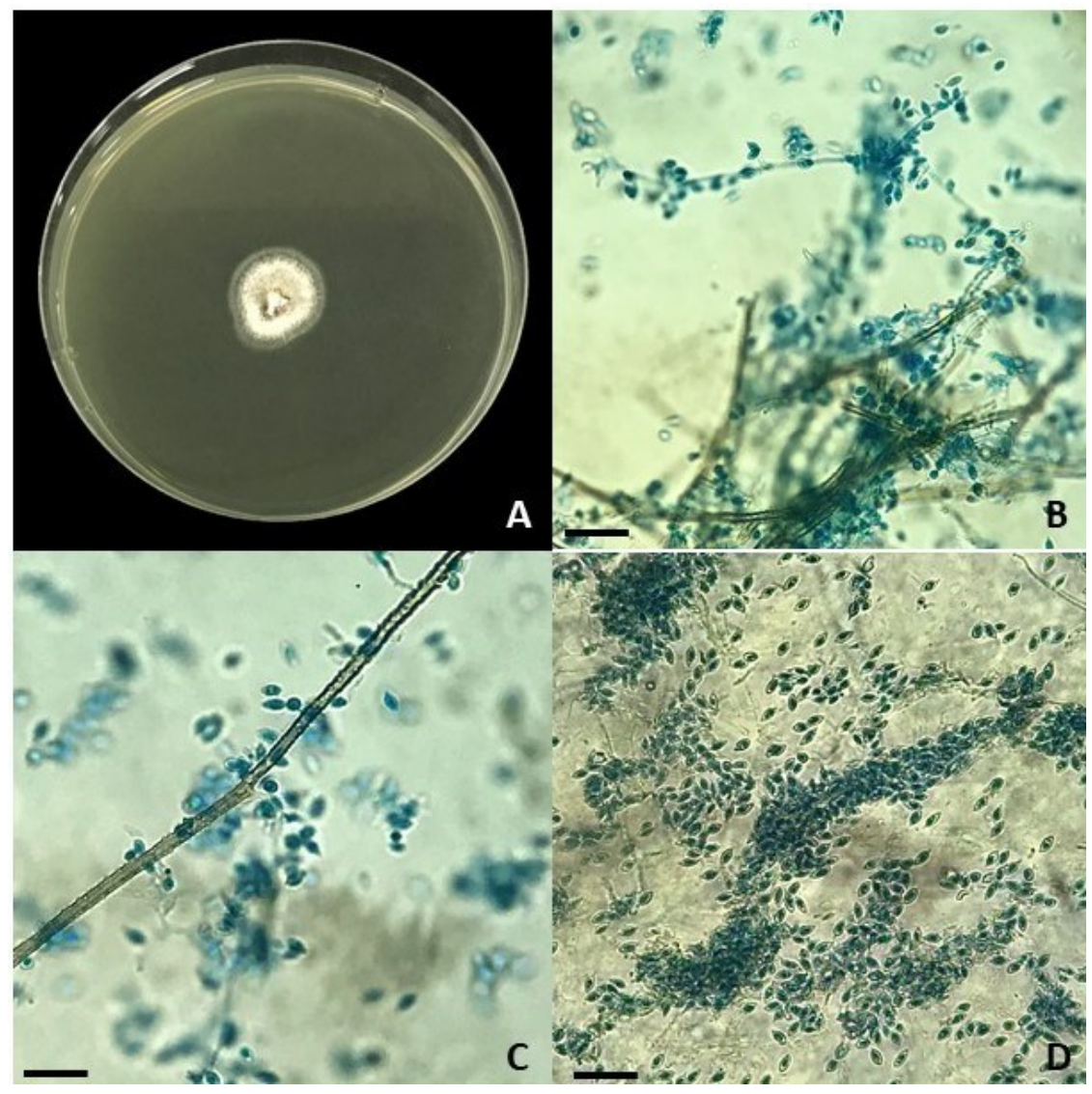

Figure 1. Seven-dayold A. levis on PDA (A), hyaline fusiform ascospores and ornamented mycelia (B-D). Scale bar $=20 \mu \mathrm{m}$.

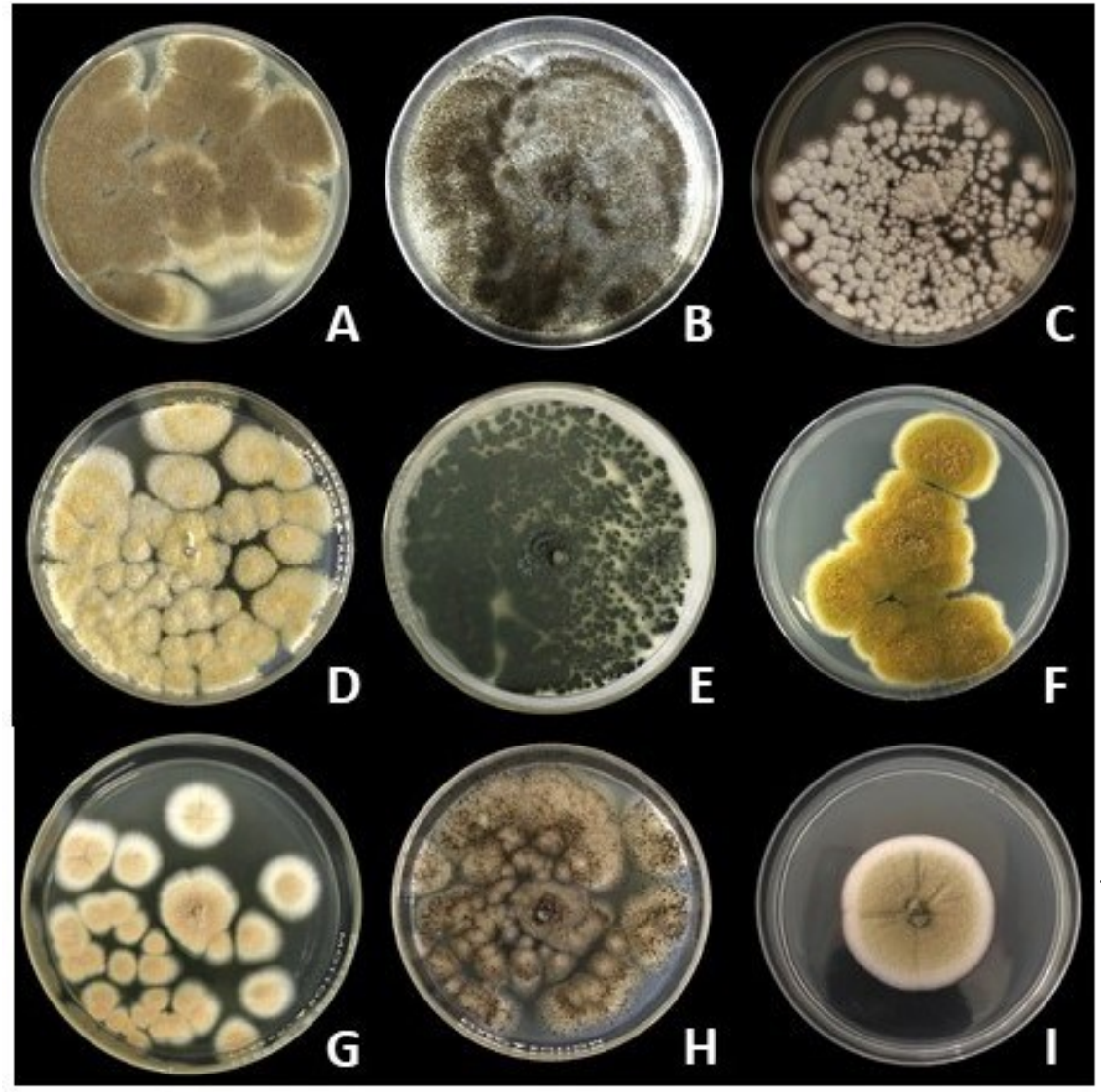

Figure 2. Seven-day-old Aspergillus species on PDA: A. aculeatus (A), A. brasiliensis (B), A. flaviceps (C), A. flavus (D), A. fumigatus (E), A. tamarii (F), A. terreus $(\mathrm{G})$, A. tubingensis $(\mathrm{H})$ and $A$. versicolor (I). 


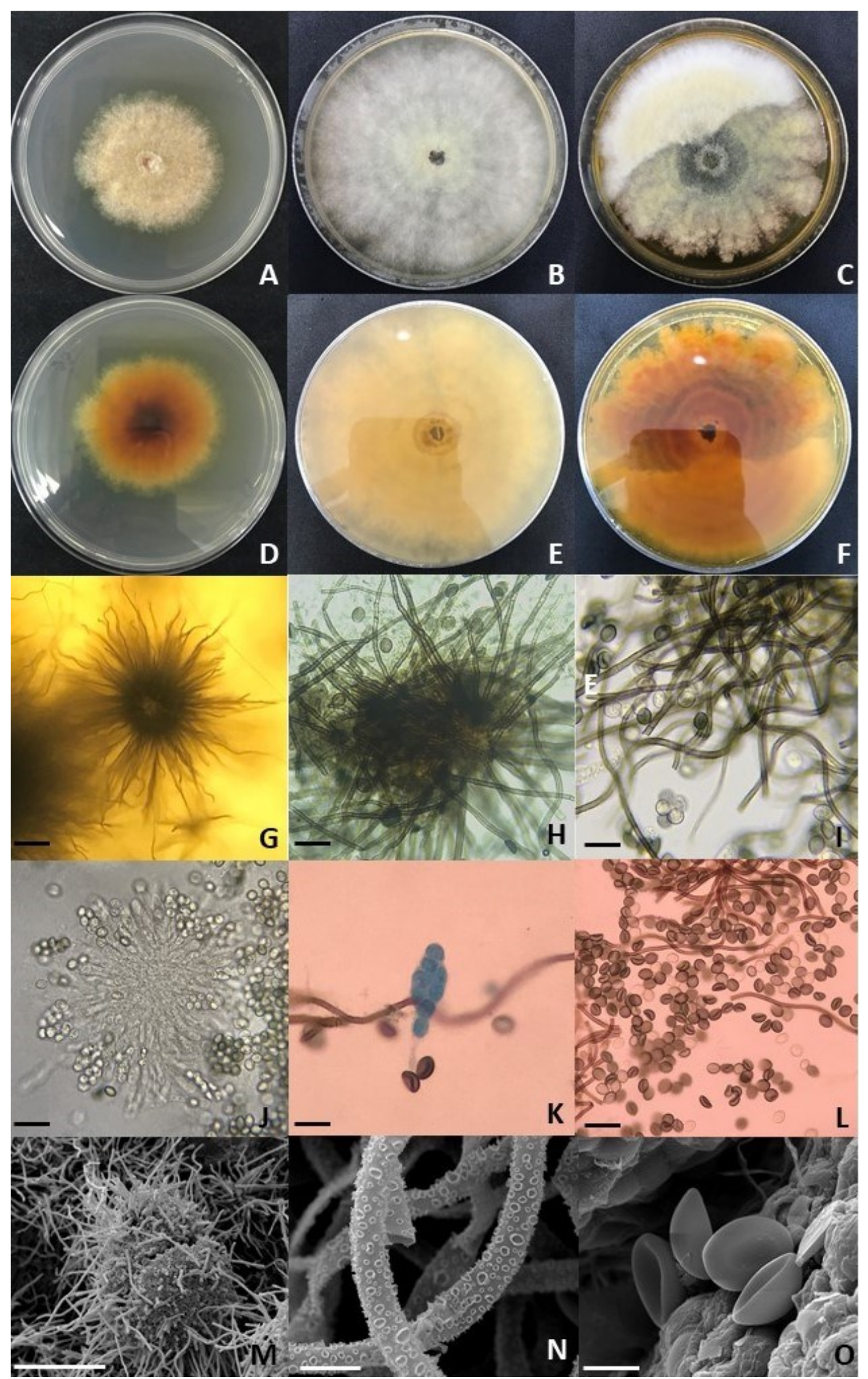

Figure 3. Seven-day-old C. globosum on PDA (A, D), yeast extract agar (YEA) (B,E), malt extract agar MEA (C,F), perithecium $(\mathrm{G}, \mathrm{H})$, ascomatal hairs $(\mathrm{I})$, fasciculate asci $(\mathrm{J})$, lactophenol-stained ascus with eight ascospores $(\mathrm{K})$ and mature ascopores $(\mathrm{L})$; scanning electron micrograph ofperithecium (M), ascomatal hairs $(\mathrm{N})$ and ascospores $(\mathrm{O})$. Scale bars: $\mathrm{G}-\mathrm{L}=10 \mu \mathrm{m} ; \mathrm{M}=100 \mu \mathrm{m}$; $\mathrm{N}, \mathrm{O}=5 \mu \mathrm{m}$. 

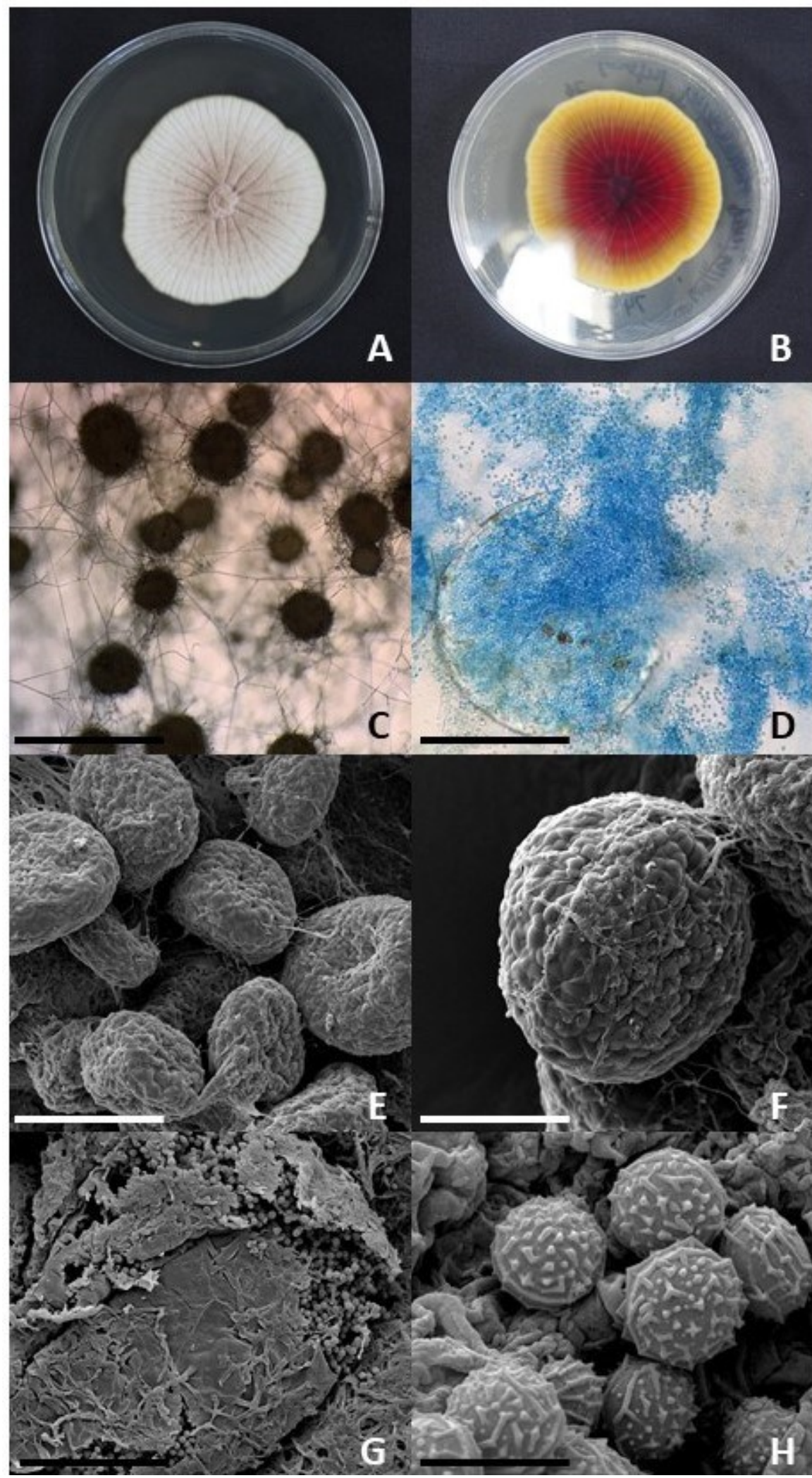

Figure 4. E. nidulans on PDA seven days after inoculation (A) and reverse side (B); intact (C) and ruptured cleistothecium with globose ascospores (D); scanning electron micrograph of cluster of cleistothecia (E) and single cleistothecium (F) showing roughened ascoma wall; ruptured cleistothecium $(\mathrm{G})$; ascospores $(\mathrm{H})$. Scale bars: $\mathrm{C}=300 \mu \mathrm{m} ; \mathrm{E}=100 \mu \mathrm{m} ; \mathrm{D}, \mathrm{F}, \mathrm{G}=50 \mu \mathrm{m} ; \mathrm{H}=3 \mu \mathrm{m}$. 


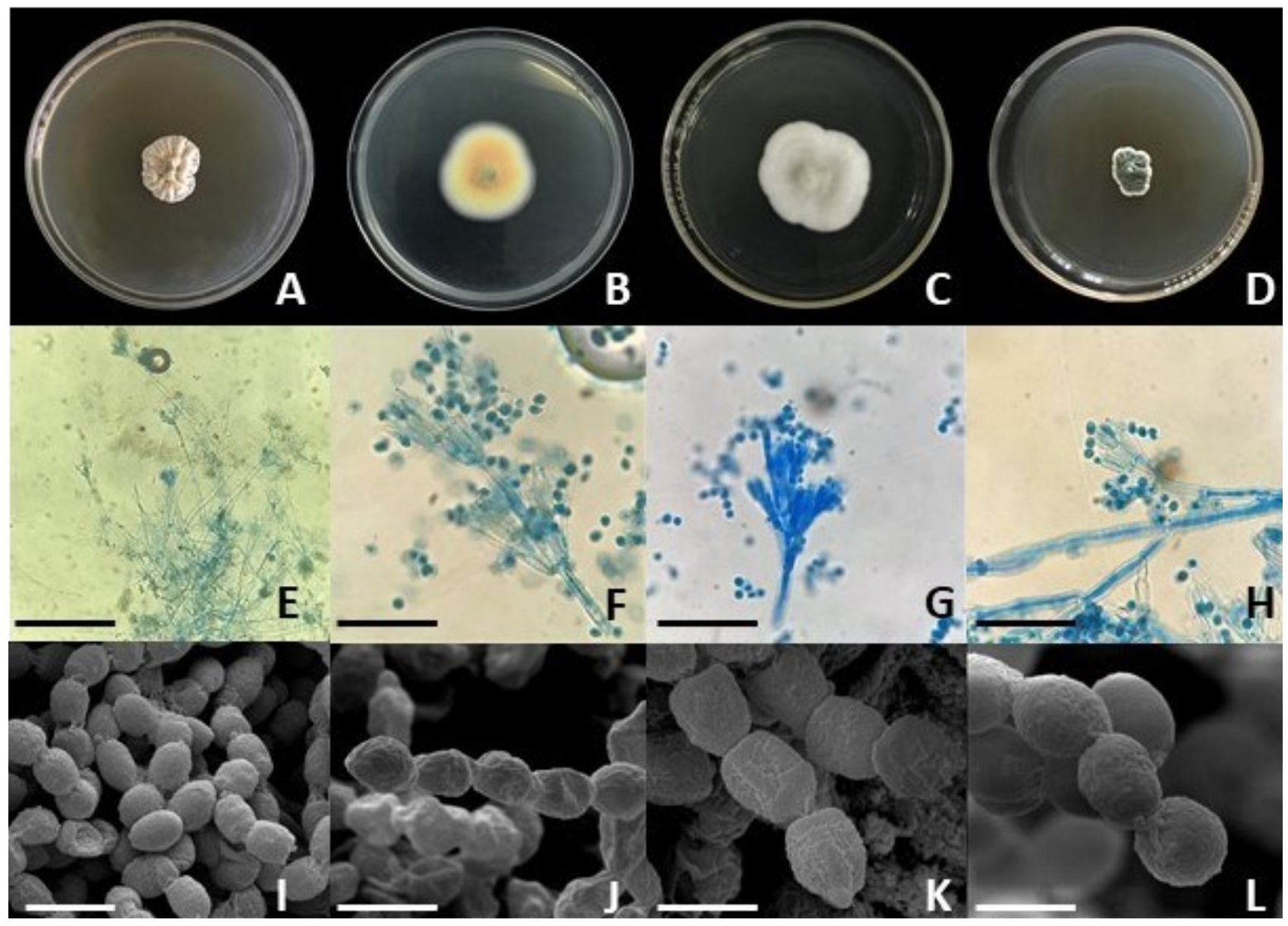

Figure 5. Seven-day-old Penicillium species on PDA: P.citrinum (A), P. pinophilum (B), P. polonicum (C) and $P$. solitum (D); micrographs of phialides and catenate conidia of : P.citrinum (E), P. pinophilum (F), P. polonicum (G) and P. solitum (H); scanning electron micrographs of conidia of : P.citrinum (I), P. pinophilum (J), P. polonicum (K) and $P$. solitum (L). Scale bars: $\mathrm{E}-\mathrm{H}=30 \mu \mathrm{m} ; \mathrm{I}=5 \mu \mathrm{m} ; \mathrm{J}-\mathrm{L}=3 \mu \mathrm{m}$.

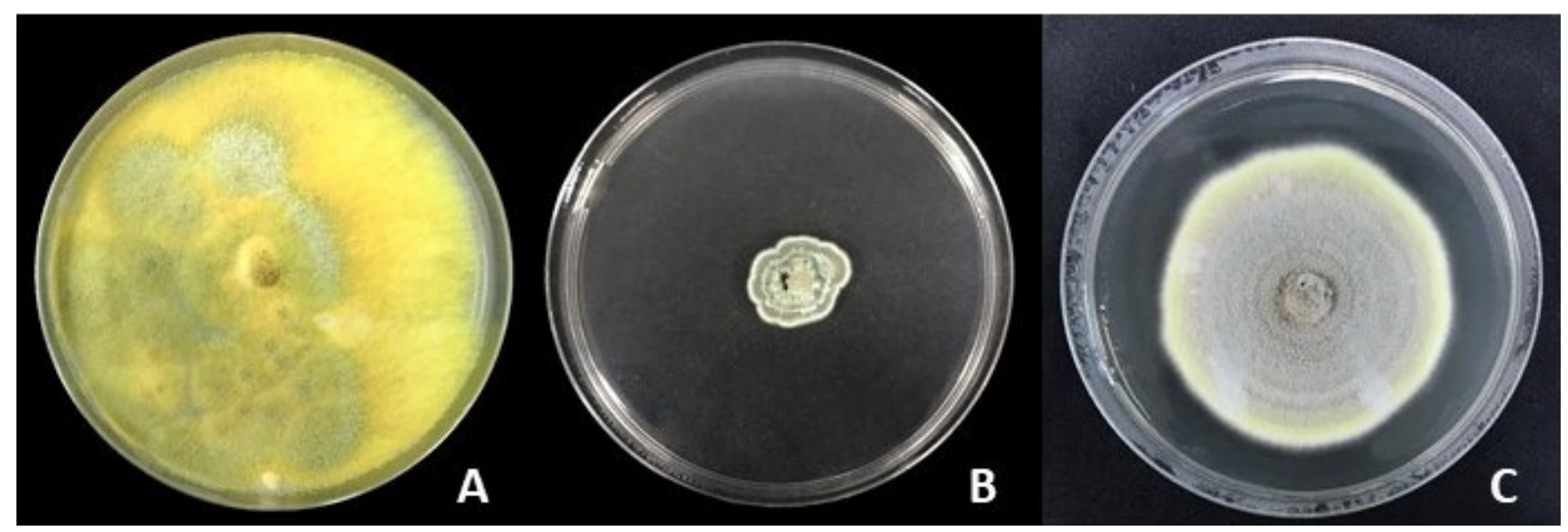

Figure 6. Seven-day-old Talaromyces species on PDA: T. verruculosus (A), T. radicus (B) and T. pinophilus (C). 

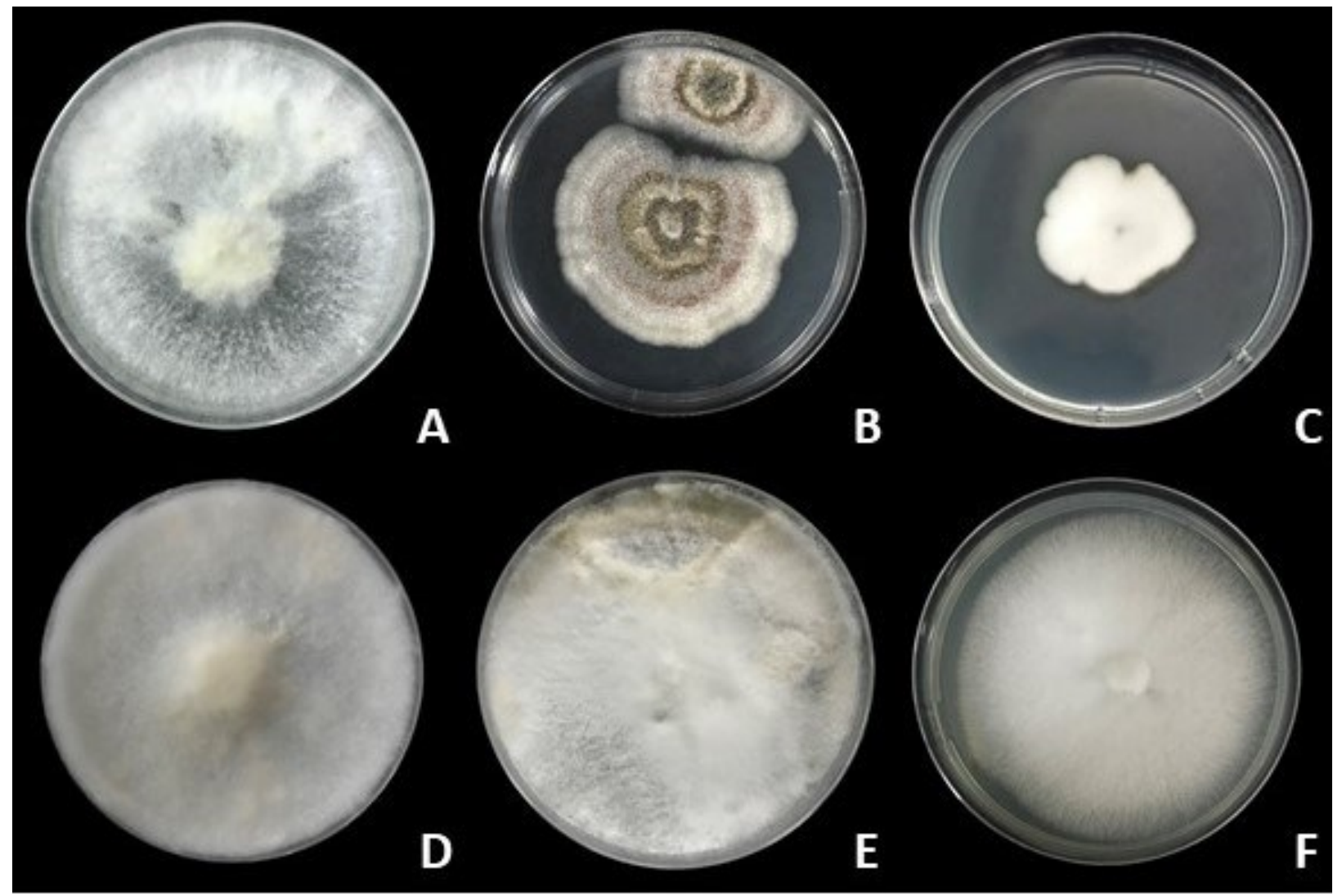

Figure 7. Basidiomycetes growing on PDA: Emmia lacerata (A), Fomitopsis meliae (B), Lentinus sp. (C), Rigidoporus vinctus (D), Schizophyllum commune (E), and Trametes maxima (F).

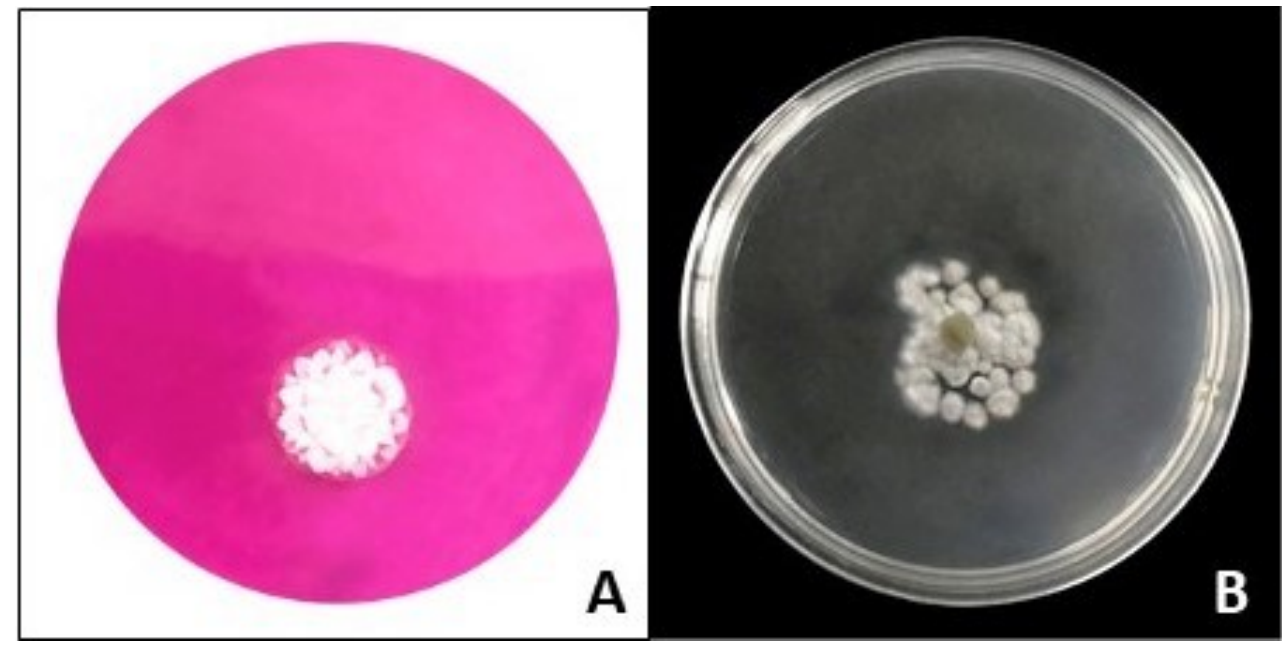

Figure 8. Mortierella sp. growing on RBA (A) and PDA (B). 
role.

\section{Fungal Colony-forming Units (CFU) at Different Sampling Depth}

Colony-forming units represent a rough approximate of the number of microorganisms in the soil sample. These CFUs, as shown in Table 2, decreased drastically as the depth of soil increased. This is to be expected as fungi are aerobic organisms and would thrive at soil depth with adequate oxygen levels. The surface soil at $0-5 \mathrm{~cm}$ depth is the area most exposed to air and is constantly subjected to soil movement and aeration. Statistical analysis showed that this specific depth has significantly higher number of soil fungi than at other depths ( $p$ $=0.0008$ ). The number of unique morphotypes also decreased, suggesting that there are fewer culturable taxa as soil sampling gets deeper. Table 2 shows that the number of morphotypes differs in number of unique species. During isolation, morphologically different fungi growing on plate were isolated and assigned an isolation code. At final identification, some of these were combined because they belong to the same species after thorough morphological and molecular analysis. Frequency of each unique species are then summarized in Table 3. Unique species refer to isolates that are morphologically and molecularly distinct after analysis.

As expected, the Aspergillus and Penicillium species, including Talaromyces, were ubiquitous in the soil strata, and occurred in all layers of the soil. These 3 genera are known for their gregarious sporulation. All Basidiomycetes, on the other hand, were not found in the deeper part of the soil. In relation to the grass cover of the sampling sites, Basidiomycetes may fall into four functional groups (Griffith and Roderick, 2008): dung fungi, litter decomposers, terricolous species and root endophytes. All these variables are found in the upper layer of the soil.

No strict plant pathogen was isolated in this study. Acrophialophora levis Samson \& T. Mahmood, on one hand, is reported to be an opportunistic human pathogen which can cause keratitis, pulmonary colonization and other serious infections (Sandoval-Denis et al., 2015).

The overall diversity is 1.07 , qualitatively described to be low. The diversity indices for each soil strata do not differ significantly from one another. It is to be emphasized, however, that this only represents culturable fungi, or those that are able to grow on synthetic media. This culture-dependent method of estimating fungal diversity may be a challenge especially when many fungi do not show diagnostic features or do not form fruiting bodies in vitro (Grube et al., 2017) and thus remain undetected for accounting and identification (Pozo et al., 2011).

In this study, the objective was to simply provide an
Table 2. Mean ${ }^{1} \mathrm{CFU}$ of culturable fungi per $\mathrm{mL}$ of soil suspension $\left(\mathrm{x} 10^{-1}\right)$ at different sampling depths of Lipa clay loam soil.

\begin{tabular}{lccc}
\hline DEPTH (cm) & $\begin{array}{c}\text { Number of } \\
\text { morphotypes }\end{array}$ & $\begin{array}{c}\text { Number of } \\
\text { unique species }\end{array}$ & $\begin{array}{c}\text { CFU/mL of soil } \\
\text { suspension (x10 }\end{array}$ \\
\hline $\begin{array}{l}\text {-1 }) \\
\text { (surface) }\end{array}$ & 24 & 20 & $90.75 a$ \\
$\begin{array}{l}\text { surface) } \\
11-20 \\
\text { (middle) }\end{array}$ & 16 & 14 & $48.00 \mathrm{~b}$ \\
$21-30$ (deep) & 21 & 15 & $43.25 \mathrm{bc}$ \\
\hline
\end{tabular}

with four replicates

Means followed by the same letter are not significantly different at $p=0.0008$ level of significance using Least Significant Difference Test

overview of fungal richness or abundance and not absolute population data. This overview based on culturability is anchored on the fact that fungi are aerobic organisms and are thus dependent on oxygen for survival. An increasing soil depth decreases oxygen level (Noll et al., 2005) and is corollary to the results that CFU will also decrease. This trend is also shown to be true even using molecular techniques in bacteria (Noll et al., 2005) and arbuscular mycorrhizal fungi (Shukla et al., 2013).

Bray-Curtis single link cluster analysis shows the similarity of taxa across the soil strata (Fig. 9). The surface layer had a $41.17 \%, 46.46 \%$ and $26.47 \%$ similarity with the subsurface, middle and deep layers, respectively. The subsurface layer had a $54.12 \%$ taxa similarity with the middle layer, while the middle layer recorded the least similarity with the deep layer at $23.53 \%$.

\section{Fungal Siderophore Identification}

Consistent with literature, majority of fungi isolated in this study are able to produce hydroxamate siderophores (Table 4). Most Ascomycetes and Basidiomycetes synthesize the hydroxamate type of siderophores, classified into four main classes: ferrichromes, fusarinines, coprogens and rhodoturulic acid (Winkelmann, 1992). On the other hand, others produce the carboxylate type which contains citric-acid and is predominantly produced by members of the phylum Zygomycota (Das et al., 2007). Renshaw et al. (2002) reported the variety of these compounds across major groups of fungi. Unlike in bacteria where siderophores are strongly correlated to taxonomy, there is limited correlation that exists among fungi and the siderophores produced. Only the species Aspergillus tamarii was observed to produce all three types of siderophores. Six species, on the other hand, did not show any siderophore production. These were Aspergillus terreus Thom, Fomitopsis meliae (Underwood) Gilbertson, Penicillium pinophilum 
Table 3. Species isolated across soil strata and corresponding frequency of occurrence in each layer of soil.

\begin{tabular}{|c|c|c|c|c|c|}
\hline \multirow{2}{*}{ Species } & surface & sub surface & middle & deep & \multirow{2}{*}{ Total FREQ. } \\
\hline & $0-5 \mathrm{~cm}$ & $6-10 \mathrm{~cm}$ & $11-20 \mathrm{~cm}$ & $21-30 \mathrm{~cm}$ & \\
\hline Acrophialophora levis & & & 1 & & 1 \\
\hline Aspergillus aculeatus & 1 & 3 & & 1 & 5 \\
\hline Aspergillus brasillensis & 10 & 3 & 2 & 1 & 16 \\
\hline Aspergillus flaviceps & & 4 & & & 4 \\
\hline Aspergillus flavus & 3 & & 4 & 1 & 8 \\
\hline Aspergillus fumigatus & 3 & 2 & 5 & 1 & 11 \\
\hline Aspergillus tamarii & & & & 1 & 1 \\
\hline Aspergillus terreus & 8 & 3 & 5 & & 16 \\
\hline Aspergillus tubingensis & 4 & 4 & 2 & 3 & 13 \\
\hline Aspergillus versicolor & 2 & 1 & 1 & 1 & 5 \\
\hline Chaetomium globosum & 4 & & & & 4 \\
\hline Emericella nidulans & & 1 & & & 1 \\
\hline Emmia lacerata & 1 & 3 & 1 & & 5 \\
\hline Fomitopsis meliae & & & 3 & & 3 \\
\hline Fusarium sublunatum & & 3 & & & 3 \\
\hline Lentinus sp. & 1 & & & & 1 \\
\hline Mortierella sp. & & & 3 & & 3 \\
\hline Penicillium citrinum & 2 & & & & 2 \\
\hline Penicillium pinophilum & 4 & 6 & 4 & & 14 \\
\hline Penicillium polonicum & 1 & & & 1 & 2 \\
\hline Penicillium solitum & 3 & & & & 3 \\
\hline Rigidoporus vinctus & & & 2 & & 2 \\
\hline Schizophyllum commune & 1 & 5 & 2 & & 8 \\
\hline Talaromyces verruculosus & 3 & & & & 3 \\
\hline Talaromyces pinophilus & 2 & & & & 2 \\
\hline Talaromyces radicus & & 2 & 2 & & 4 \\
\hline Trametes maxima & 1 & 4 & 4 & & 9 \\
\hline Trichoderma erinaceum & 3 & & & & 3 \\
\hline Trichoderma harzianum & 1 & & 1 & & 2 \\
\hline Total Frequency & 58 & 44 & 41 & 10 & 156 \\
\hline Total Number of Species & 20 & 13 & 15 & 8 & 29 \\
\hline Shannon Diversity Index & 1.19 & 1.10 & 1.12 & 0.86 & 1.07 \\
\hline
\end{tabular}

Hedgcock, Talaromyces verruculosus (=Penicillium verrucolosum B. Peyronel), Trichoderma erinaceum Bissette, C.P. Cubicek \& Szacaks and Trichoderma harzianum Rifai.

The effect of environment on siderophore production has been reported in literature. A comparison of terrestrial and marine fungal isolates on their siderophore production revealed that although the nature of siderophores is independent of habitat, some fungi had more potent production than their counterparts from a different habitat. Terrestrial Aspergillus niger van Tieghem, for instance, had better production than its marine counterpart while marine Aspergillus versicolor (Vuillemin) Tiraboschi had more siderophores than its terrestrial counterpart (Baakza et al., 2004). Similar findings were reported by Vala et al. (2006) noting that difference in quantity of siderophores is a natural biological phenomenon. This points to an interesting search for fungal isolates from unique niches in a 
Table 4. Siderophore production of fungal isolates.

\begin{tabular}{|c|c|c|c|c|}
\hline Species & Phylum & Hydroxamate & Catecholate & Carboxylate \\
\hline Aspergillus aculeatus & Ascomycota & + & - & - \\
\hline Aspergillus brasillensis & Ascomycota & + & - & - \\
\hline Aspergillus flaviceps & Ascomycota & + & - & - \\
\hline Aspergillus flavus & Ascomycota & + & - & - \\
\hline Aspergillus fumigatus & Ascomycota & + & - & - \\
\hline Aspergillus tamarii & Ascomycota & + & + & + \\
\hline Aspergillus terreus & Ascomycota & - & - & - \\
\hline Aspergillus tubingensis & Ascomycota & + & - & - \\
\hline Aspergillus versicolor & Ascomycota & + & + & - \\
\hline Chaetomium globosum & Ascomycota & + & - & - \\
\hline Emericella nidulans & Ascomycota & + & - & - \\
\hline Emmia lacerata & Basidiomycota & + & - & - \\
\hline Fomitopsis meliae & Basidiomycota & - & - & - \\
\hline Fusarium sublunatum & Ascomycota & + & - & - \\
\hline Lentinus sp. & Ascomycota & + & - & - \\
\hline Mortierella $\mathrm{sp}$. & Zygomycota & + & - & - \\
\hline Penicillium citrinum & Ascomycota & + & - & - \\
\hline Penicillium pinophilum & Ascomycota & - & - & - \\
\hline Penicillium polonicum & Ascomycota & + & - & - \\
\hline Penicillium solitum & Ascomycota & + & - & - \\
\hline Rigidoporus vinctus & Basidiomycota & + & - & - \\
\hline Schizophyllum commune & Basidiomycota & + & - & - \\
\hline Talaromyces verruculosus & Ascomycota & - & - & - \\
\hline Talaromyces pinophilus & Ascomycota & + & - & - \\
\hline Talaromyces radicus & Ascomycota & + & - & - \\
\hline Trametes maxima & Basidiomycota & + & - & - \\
\hline Trichoderma erinaceum & Ascomycota & - & - & - \\
\hline Trichoderma harzianum & Ascomycota & - & - & - \\
\hline
\end{tabular}

(+) positive/ producing; (-) negative/ not producing 


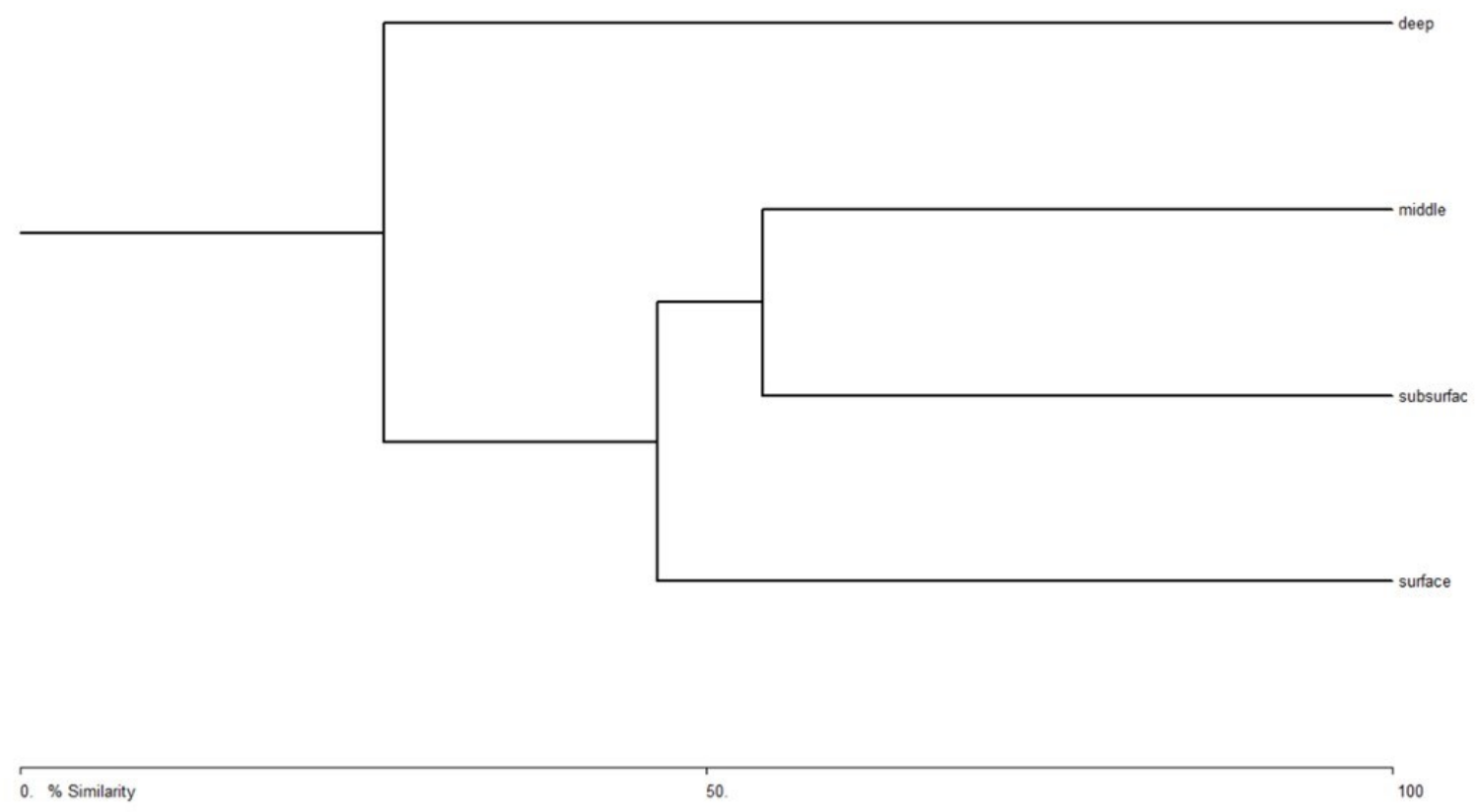

Figure 9. Results of the Bray-Curtis cluster analysis (single link) of soil strata with respect to fungal taxa.

comprehensive bioprospecting research.

Although siderophores are specific for iron, fungal siderophores are known to bind with other metals such as cadmium, lead, copper, magnesium, chromium, gallium, manganese and radionuclides at varying capacities (Nair et al., 2007) and thus is a potential mechanism for protection against heavy metal toxicity. Fusarium solani (Martius) Saccardo, for example, produces siderophores that contribute to the solubilization of copper and zinc in vitro (Hong et al., 2010).

The identification of fungi and the corresponding siderophores they produce can be useful especially in remediating metal-contaminated sites. Evidence available in literature highlights the central role of siderophores in the mobility of soil amendments. In the remediation of highlycontaminated soils, siderophores are extremely effective in solubilizing and increasing the mobility of a wide range of metals such as $\mathrm{Cd}, \mathrm{Cu}, \mathrm{Ni}, \mathrm{Pb}, \mathrm{Zn}$, and actinides $\mathrm{Th}(\mathrm{IV}), \mathrm{U}(\mathrm{IV})$ and $\mathrm{Pu}(\mathrm{IV})$ (Ahmed and Holmström, 2014). The production of siderophores is site-specific, which means that unique ecosystems may trigger production of siderophores of fungal species as compared to their relatives from other habitats. Thus, exploring niches is essential as a means of bioprospecting for fungal species that can produce a wide range of siderophore compounds. As most soils are acidic, fungi have an advantage over their bacterial counterparts. Under $\mathrm{pH}$ conditions of 3-4, organisms that produce hydroxamate siderophores, mainly by fungi, have an advantage due to the extreme acid stability of these molecules.

Mycoremediation may address metal contamination concerns because of their intrinsic morphological and physiological characters, including their ability to produce siderophores. Because fungal species are versatile, they can be harnessed to withstand the dynamic soil environment as well as the metal pollutants present in it. The use of soil fungi, especially when in consortia, can be advantageous for higher metal scavenging and more stability against environmental fluctuations (Mishra and Malik, 2014) and can rely on the different mechanisms by which fungi detoxify metal contaminants (Pan et al., 2010).

\section{Conclusion and Recommendation}

This study is the first to comprehensively report the species of fungi in Lipa clay loam soil at UPLB. Twenty-nine species of fungi were isolated in this study. Most notably, hyphomycetes were the common isolates. A culture-dependent method resulted in low diversity of fungi. Nonetheless, species represented major groups of soil mycobiota, from hyphomycetes to coelomycetes of the phylum Ascomycota, to the Zygomycota and Basidiomycota groups. This current study showed at which soil 
depth each species would most likely occur. Finally, results of siderophore identification were found to be in conformity with existing literature.

It is recommended that multiple isolation techniques be employed as well as direct soil DNA extraction to truly represent fungal diversity and eliminate the culture-dependent bottleneck. Siderotyping may be done to elucidate their functional role in responses of fungi to metal stress in actual metal exposure.

\section{Acknowledgement}

The authors acknowledge the funding by the Department of Science and Technology through the ASTHRDP Grant provided to the lead author. Researchers likewise acknowledge the assistance of the Soil Microbiology laboratory (Mr. Conrad Mamaril, Ms. Maria Czet Fulleros, Ms. Roselle Madayag, Mrs. Tess Q. Lantican, Ms. Shaira Granada, Mr. Patrick Cuenca, Prof. Lester Pide),Mr. Jeremy Roy Augustus Gomez (UPLB Plant Pathology) and Mr. Roy Boten (Bureau of Plant Industry) for the handling of specimens for identification.

\section{Literature Cited}

Ahmed, E. \& S.J. Holmström, 2014. Siderophores in environmental research: roles and applications. Microbial Biotechnology, 7: 196-208.

Baakza, A., A.K. Vala, B.P. Dave \& H.C. Dube, 2004. A comparative study of siderophore production by fungi from marine and terrestrial habitats. Journal of Experimental Marine Biology and Ecology, 311: 1-9.

Bridge, P. \& B. Spooner, 2001. Soil fungi: diversity and detection. Plant and Soil, 232: 147-154.

Carating, R.B., R.G. Galanta \& C.D. Bacatio, 2014. The Soils of the Philippines. Springer Science+Business Media, Dordrecht, the Netherlands. 346 pp.

Das, A., R. Prasad, A. Srivastava, P.H. Giang, K. Bhatnagar \& A. Varma, 2007. Fungal siderophores: structure, functions and regulation. In : Varma, A. \& Chincholkar, S.B., (eds.), Microbial Siderophores. Springer, Berlin \& Heidelberg. pp. $1-42$.

Dave, B.P. \& H.C. Dube, 2000. Chemical characterization of fungal siderophores. Indian Journal of Experimental Biology, 38: 56-62.

Griffith, G.W. \& K. Roderick, 2008. Saprotrophic basidiomycetes in grasslands: distribution and function. In: Boddy, L., Frankland, J.C. \& van West, P., (eds.), British Mycological Society Symposia Series. Volume 28, Academic Press, New York. pp. 277-299.
Grube, M., E. Gaya, H. Kauserud, A.M. Smith, S.V. Avery, S.J. Fernstad, L. Muggia, M.D. Martin, E. Tove, U. Koljalg, \& M. Bendiksby, 2017. The next generation fungal diversity researcher. Fungal Biology Reviews 31: 124-130.

Hong, J.W., J.Y. Park \& G.M. Gadd, 2010. Pyrene degradation and copper and zinc uptake by Fusarium solani and Hypocrea lixii isolated from petrol station soil. Journal of Applied Microbiology, 108: 2030-2040.

Kumari, S. \& V. Kaviyarasan, 2014. Screening of siderophores in basidiomycetes. Journal of Pharmaceutical and Biomedical Sciences, 4: 291-297.

Loper, J.E. \& J.S. Buyer, 1991. Siderophores in microbial interactions on plant surfaces. Molecular Plant-Microbe Interactions, 4: 5-13.

McAleece, N., J.D.G. Gage, P.J.D. Lambshead \& G.L.J. Paterson. 1997. Biodversity professional statistics analysis software. Jointly developed by the Scottish Association for Marine Science and the Natural History Museum London.

Mishra, A. \& A. Malik, 2014. Novel fungal consortium for bioremediation of metals and dyes from mixed waste stream. Bioresource Technology, 171: 217-226.

Nair, A., A.A. Juwarkar \& S.K. Singh, 2007. Production and characterization of siderophores and its application in arsenic removal from contaminated soil. Water, Air, and Soil Pollution, 180: 199-212.

Noll, M., D. Matthies, P. Frenzel, M. Derakshani \& W. Liesack, 2005. Succession of bacterial community structure and diversity in a paddy soil oxygen gradient. Environmental Microbiology, 7: 382-395.

Pan, J.H., Y.C. Lin, N. Tan \& T.C. Gu, 2010. Cu (II): a "signaling molecule" of the mangrove endophyte Fusarium oxysporum ZZF51? Biometals, 23: 1053-1060.

Payne, S.M., 1994. Detection, isolation and characterization of siderophores. Methods in Enzymology, 325: 329-344.

Pozo, M.I., C.M. Herrera \& P. Bazaga, 2011. Species richness of yeast communities in floral nectar of southern Spanish plants. Microbial Ecology, 61: 82-91.

Renshaw, J.C., G.D. Robson, A.P. Trinci, M.G. Wiebe, F.R. Livens, D. Collison \& R.J. Taylor. 2002. Fungal siderophores: structures, functions and applications. Mycological Research, 106: 1123-1142.

Samuels, G.J. \& P.K. Hebbar, 2015. Trichoderma: Identification and Agricultural Applications. American Phytopathological Society Press, St. Paul, MN. 196 pp.

Sandoval-Denis, M., J. Gené, D.A. Sutton, N.P. Wiederhold \& J. Guarro, 2015. Acrophialophora, a poorly known fungus with clinical significance. Journal of Clinical Microbiology, 53: 1549-1555.

Shenker, M., I. Oliver, M. Helmann, Y. Hadar \& Y. Chen, 1992. 
Utilization by tomatoes of iron mediated by a siderophore produced by Rhizopus arrhizus. Journal of Plant Nutrition, 15: 2173-2182.

Shukla, A., D. Vyas \& J. Anuradha, 2013. Soil depth: an overriding factor for distribution of arbuscular mycorrhizal fungi. Journal of Soil Science and Plant Nutrition, 13: 2333.

Vala, A.K., B.P. Dave \& H.C. Dube, 2006. Chemical characterization and quantification of siderophores produced by marine and terrestrial aspergilli. Canadian Journal of Microbiology, 52: 603-607.

VanderMolen, K.M., B.A. Darveaux, C.J. Pearce \& N.H. Oberlies, 2012. Chemical epigenetics induce additional secondary metabolites in a filamentous fungus. Planta Medica, 78: PI65.

Watanabe, T., 2010. Pictorial Atlas of Soil and Seed Fungi: Morphologies of Cultured Fungi and Key to Species, $3^{\text {rd }}$ Ed. CRC Press, Boca Raton, FL. 426 pp.

Winkelmann, G., 1992. Structures and functions of fungal siderophores containing hydroxamate and complexone type iron binding ligands. Mycological Research, 96: 529-534. 